УдК 536.248.2:532.529.5

А. В. Дороченко ${ }^{\bowtie}$ В. Х. Кириллов, А. Р. Антонова, К. В. Людницкий, В. В. Мелехин

Одесская национальная академия пищевых технологий, ул. Канатная, 112, г. Одесса, 65039, Украина

$\triangle$ e-mail: dor_av@i.ua

\title{
ИСПАРИТЕЛЬНЫЕ ОХЛАДИТЕЛИ ГАЗОВ И ЖИДКОСТЕЙ ПРЯМОГО И НЕПРЯМОГО ТИПОВ СО СНИЖЕННЫМ ПРЕДЕЛОМ ОХЛАЖДЕНИЯ
}

Разработаны принципиальные решения испарительных водо- и воздухоохладителей прямого и непрямого типа со сниженным пределом охлаждения (по отношению к температуре мокрого термометра поступающего в охладитель воздушного потока). Насадочная часть тепломассообменных аппаратов пленочного типа выполнена на основе многоканальных композиций из полимерных материалов с каналами сложно конфигураџии. Предложена математическая модель, описывающая процессы совместного тепло-массообмена в испарительных охладителях непрямого типа НИОг и выполнен, на основании полученных авторами экспериментальных данных по эффективности процессов тепло-массообмена, сравнительный анализ возможностей разработанных охладителей. В эксперименте варьировали начальные параметры (температуру и влагосодержание) воздушного потока и соотношения контактирующих потоков газа и жидкости. Экспериментально установлены предельные нагрузки по газу и жидкости и рассмотрен вопрос об опасности «захлебывания» «мокрых» каналов насадки. Получены данные по задержке жидкости в насадочном слое, определяющей реальную поверхность контактирования потоков газа и жидкости. Показана опасность реконденсачии во вспомогательном воздушном потоке в НИОг и НИО-Rг с ростом глубины охлаждения, когда вспомогательный воздушный поток в пределах насадочной части может оказаться полностью насыщенным влагой.

Ключевые слова: Непрямое испарительное охлаждение; Тепломассообменная аппаратура; Пленочные течения; Задержка жидкости; Эффективность прочесса.

О. В. Дорошенко, В. Х. Кириллов, А. Р. Антонова, К. В. Людницький, В. В. Мелехін

Одеська національна академія харчових технологій, вул. Канатна, 112, м. Одеса, 65039, Україна

\section{ВИПАРНІ ОХОЛОДЖУВАЧІ ГАЗІВ І РІДИН ПРЯМОГО ТА НЕПРЯМОГО ТИПІВ ЗІ ЗНИЖЕНОЮ МЕЖЕЮ ОХОЛОДЖЕННЯ}

Розроблено принципові рішення випарних водо- і повітроохолоджувачів прямого і непрямого типу зі зниженою межею охолодження (по відношенню до температури мокрого термометру повітряного потоку, щзо надходить в охолоджувач). Насадкова частина тепломасообмінних апаратів плівкового типу виконана на основі багатоканальних композицій з полімерних матеріалів з каналами складної конфігурації. Запропоновано математичну модель, щзо описує процеси спільного тепло-масообміну в випарних охолоджувачах непрямого типу $\mathrm{HBO}$, а також виконаний, на підставі отриманих авторами експериментальних даних $з$ ефективності процесів тепломасообміну, порівняльний аналіз можливостей розроблених охолоджувачів. В експерименті варіювали початкові параметри (температуру і вологовміст) повітряного потоку $і$ співвідношення потоків газу і рідини, які контактують. Експериментально встановлено граничні навантаження для газу і рідини, та розглянуто питання про небезпеку «захлинання» «мокрих» каналів насадки. Отримано дані про затримку рідини в насадковому шарі, яка визначає реальну поверхню контактування потоків газу і рідини. Показано небезпеку реконденсаціі у допоміжному повітряному потоиі в НВОг і HBO-Rz з ростом глибини охолодження, коли допоміжний повітряний потік в межах насадкової частини може виявитися повністю насиченим вологою.

Ключові слова: Непряме випарне охолодження; Тепломасообмінна апаратура; Плівкові течї̈; 3атримка рідини; Ефективність процесу.

This work is licensed under the Creative Commons Attribution International License (CC BY). http://creativecommons.org/licenses/by/4.0/ 


\section{ВВЕДЕНИЕ}

Практический интерес к возможностям испарительных охладителей как прямого, так и непрямого типов (ИО) газов и жидкостей непрерывно растет, о чем свидетельствуют публикации в ведущих мировых научных изданиях. Особый интерес вызывают ИО нового поколения, непрямого типа, со сниженным пределом охлаждения [5-9]. Разработанные решения охватывают нужды энергетики, химической и пищевой промышленности и позволяют решать задачи охлаждения, не прибегая к традиционной парокомпрессионной технике, либо снижая ее долевое участие. Это позволяет также существенно улучшить их эко-энергетические показатели [10].

\section{І. ИСПАРИТЕЛЬНЫЕ ВОЗДУХООХЛАДИТЕЛИ НЕПРЯМОГО ТИПА СО СНИЖЕННЫМ ПРЕ- ДЕЛОМ ОХЛАЖДЕНИЯ. ОСНОВНЫЕ ПРИН- ЦИПИАЛЬНЫЕ РЕШЕНИЯ}

В испарительном воздухоохладителе непрямого типа НИОг (рисунок 1), получившем наибольшее распространение в последние годы $[1,5-9,11-12]$, полный воздушный поток (П), поступающий на охлаждение, делится на две части. Вспомогательный поток воздуха (В) поступает в «мокрую» часть охладителя, где контактирует с водяной пленкой, стекающей по поверхностям канала и обеспечивает испарительное охлаждение воды, которая, в свою очередь, охлаждает бесконтактно через разделяющую стенку основной воздушный поток (O). Этот «продуктовый» поток воздуха охлаждается при неизменном влагосодержании, что обеспечивает преимущества при создании на основе НИО систем кондиционирования воздуха (СКВ).

Вспомогательный воздушный поток «В» выносит все тепло из НИО в «связанном» виде, его температура также понижается и влагосодержание возрастает. Температура воды, рециркулирующей в цикле, сохраняет неизменное значение и оказывается на несколько градусов выше температуры мокрого термометра поступающего в НИО воздуха (рисунок 7). Эта температура зависит от соотношения воздушных потоков в НИО и является пределом охлаждения для обоих воздушных потоков.

Испарительные воздухоохладители могут быть обычного (НИОг, рисунок 1) и регенеративного типов НИО-Rг (рисунок 2В) [7-12], отличаясь местом разделения воздушного потока, поступающего в охладитель. Во втором случае обеспечивается более глубокое охлаждение воздуха, поскольку здесь процесс испарительного охлаждения воды в «мокрой» части аппарата ориентирован на температуру мокрого термометра воздуха, уже прошедшего охлаждение в «сухой» части охладителя и пределом охлаждения, в принципе, является температура точки росы наружного воздуха. Такая схема предпочтительна для глубокого охлаждения сред, но характеризуется и более высоким уровнем энергозатрат. Обстоятельному изу- чению возможностей охладителя регенеративного типа НИО-Rг посвящены исследования [7-9].

На основе НИО также может быть построен комбинированный низкотемпературный водоохладитель (солнечная холодильная система СХC) по формуле [НИО-ГРД], где испарительный водоохладитель, градирня (ГРД), работает на основном, охлажденном в НИО, воздушном потоке. В этом случае предел испарительного охлаждения для градирни (температура поступающего в нее воздуха по мокрому термометру), существенно ниже, чем у наружного воздуха [5-6, 11-12].

На рисунке 3 представлены основные элементы и принципы компоновки воздухоохладителей НИОг. Насадка НИОг составлена из «сухого» и «мокрого» элементов (многоканальных плит), каналы в которых имеют взаимноперпендикулярные направления. «Мокрая» часть насадки НИОг комплектуется водораспределителем и водосборником. Поскольку вспомогательный воздушный поток покидает аппарат достаточно холодным (его температура практически равна температуре основного продуктового воздушного потока, а основную часть тепла он выносит из системы в «связанном» виде, рисунок 1Г), целесообразно использование этого потенциала для предварительного охлаждения, например, поступающего в НИОг полного воздушного потока.

«Мокрые» каналы насадки, предназначенные для непосредственного взаимодействия вспомогательного воздушного потока и рециркулирующей воды, имеют сложную форму, обеспечивающую хорошее распределение жидкости (включая задержку жидкости, которая обеспечивает реальную поверхность тепломасообмена в аппарате), стекающей по поверхности элементов насадки. Вопрос о качестве распределения жидкости по поверхности насадочных элементов принципиально важен, особенно в случае использования полимерных материалов для конструирования насадки [4-6]. Здесь может использоваться либо сложнопрофилированный тип канала, либо регулярная шероховатость поверхности насадочных элементов. Схема контактирования по воздушным потокам поперечноточная, и в «мокрой» части по воде и вспомогательному воздушному потоку противоточная. Величина эквивалентного диаметра каналов одинакова для «сухой» и «мокрой» частей насадки, и, в зависимости от решаемой задачи, в среднем составляет: $d=15$ - 20 мм; параметр регулярной шероховатости поверхности (РШ) $k=p / e=10-14$ (где $p-$ шаг, а $e-$ высота выступа регулярной шероховатости поверхности РШ) [1-2].

Регенеративный вариант воздухоохладителя непрямого типа НИО-Rг представлен на рисунке 2B. Принцип устройства и образования моноблока здесь полностью идентичен рассмотренному выше для НИО, с той разницей, что разделение полного воздушного потока (П) происходит не на входе в моноблок, а на выходе, так что полный воздушный поток предварительно охлаждается в «сухой» части аппарата, что повышает потенциал последующего испарительного охлаждения от ступени к ступени аппарата. 
Испарительный воздухоохладитель непрямого типа НИОг. A Indirect Evaporative cooling IECg

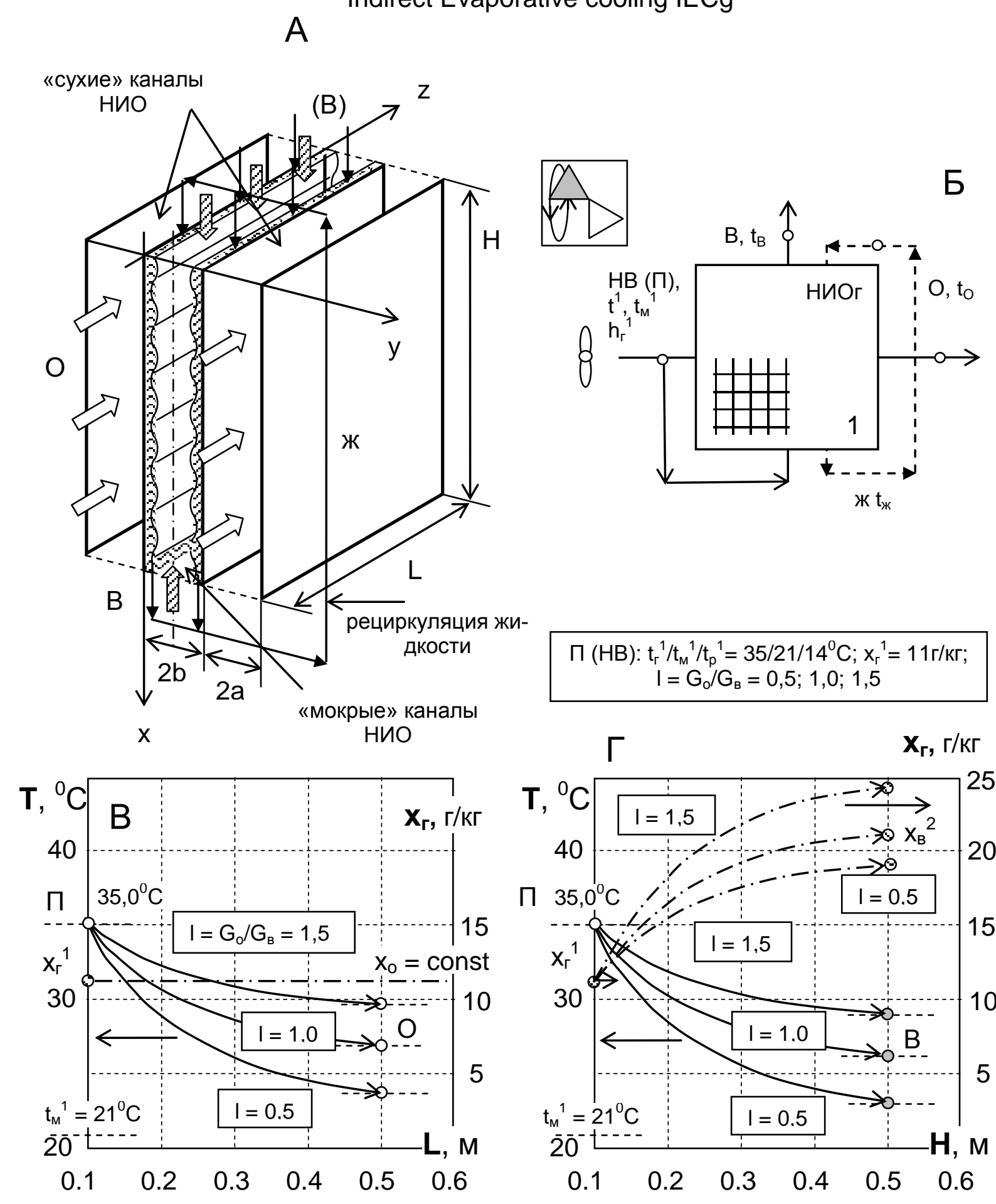

Рисунок 1 - К моделированию процессов совместного тепломассообмена при испарительном охлаждении воздуха в воздухоохладителе непрямого типа НИО. А и Б - расчетная принципиальная схема НИОг. Результаты расчетов: В и Г - изменение температуры и влагосодержания основного «О» и вспомогательного «В» воздушных потоков по длине (L) и высоте $(\mathrm{H})$ модуля НИОг $\left(l=G_{\mathrm{o}} / G_{\mathrm{B}}: 1-0,5 ; 2-1,0 ; 3-1,5\right)$ 


\section{II. МОДЕЛИРОВАНИЕ ПРОЦЕССОВ СОВМЕСТ- НОГО ТЕПЛОМАССООБМЕНА В ИСПАРИ- ТЕЛЬНОМ ВОЗДУХООХЛАДИТЕЛЕ НЕПРЯ- МОГО ТИПА НИОг}

Для описания процессов тепломассообмена в НИОг при условии материальной однородности потоков выделим элемент насадки протяжённостью $0 \leq x$ $\leq H,-a \leq y \leq b, 0 \leq z \leq L$ (рисунок $1 \mathrm{~A})$. Основной поток воздуха охлаждается через разделяющую стенку за счёт испарительного охлаждения воды, стекающей в виде плёнки. При этом вспомогательный воздушный поток находится в непосредственном контакте с жидкостью (схемы контактирования потоков газа и жидкости в «мокрых» каналах рассмотрены как прямотак и противоточные). Уравнения совместного тепломасообмена в НИОг и соответствующие условия сопряжения в форме уравнений пограничного слоя:

- для жидкости $(0 \leq x \leq H, 0 \leq y \leq h(h-$ толщина слоя жидкости), $0 \leq z \leq l)$, температура $t_{\rightsquigarrow}=t_{\rightsquigarrow}(x$, $y, z)$ определяется из уравнения:

$$
W_{\varkappa}(y) \frac{\partial t_{\mathscr{K}}}{\partial x}=a_{\varkappa} \frac{\partial^{2} t_{\mathscr{⿰}}}{\partial y^{2}},
$$

условие на входе, при $x=0$, имеет вид:

$$
t_{\varkappa c}(0, y, z)=t_{a}^{0}
$$

- для вспомогательного потока газа «В» $(0 \leq x \leq$ $H, h \leq y \leq b, 0 \leq z \leq l)$, температура $t_{B}=t_{B}(x, y, z)$ и парциальное давление пара $p_{n}=p_{n}(x, y, z)$ определяются уравнениями:

$$
\begin{gathered}
W_{B}(y) \frac{\partial t_{B}}{\partial x}=\frac{\partial}{\partial y}\left[\left(a_{2}+a_{2}^{T}\right) \frac{\partial t_{B}}{\partial y}\right], \\
W_{B}(y) \frac{\partial p_{n}}{\partial x}=R_{n} T_{B} \frac{\partial}{\partial y}\left[\left(D_{2}+D_{2}^{T}\right) \frac{\partial p_{n}}{\partial y}\right],
\end{gathered}
$$

при $x=0: t_{B}=t_{B}^{0}, p_{n}=p_{n}^{0} ;$ при $y=b$ : $\frac{\partial t_{B}}{\partial y}=0, \quad \frac{\partial p_{n}}{\partial y}=0$.

- для основного воздушного потока «О» $(0 \leq x \leq$ $H,-a \leq y \leq 0,0 \leq z \leq \mathrm{L})$ температура $t_{O}=t_{O}(x, y, z)$ определяется из уравнения:

$$
W_{O}(y) \frac{\partial t_{O}}{\partial x}=\frac{\partial}{\partial y}\left[\left(a_{2}+a_{z}^{T}\right) \frac{\partial t_{O}}{\partial y}\right],
$$

при $z=0: t_{O}=t_{O}^{0} ;$ при $y=-a$ :

$$
\frac{\partial t_{O}}{\partial y}=0
$$

- условия сопряжения: на стенке при $y=0$, $q_{0}=k_{\alpha}\left(t_{B}-t_{\varkappa}\right)$, где $q_{0}-$ тепловой поток, $k-$ коэффициент теплопередачи через стенку толщиной $\delta_{c m}$ и теплопроводностью $\lambda_{c m}$ :

$$
k=\frac{1}{\frac{1}{\alpha_{0}}+\frac{\delta_{c m}}{\lambda_{c m}}+\frac{1}{\alpha_{B}}} .
$$

На поверхности раздела, когда $y=h p_{n}=p$ ”, $q=q_{\alpha}+q_{\beta}$. В результате осреднения, используя законы Ньютона и Дальтона, получим систему уравнений:

$$
\left\{\begin{array}{l}
\frac{\partial t_{\mathscr{H}}}{\partial x}=a_{1}\left(t_{B}-t_{\mathscr{H}}\right)+b_{1}\left(p-p^{\prime \prime}\right)+c_{1}\left(t_{O}-t_{\mathscr{H}}\right) \\
\frac{\partial t_{B}}{\partial x}=a_{2}\left(t_{\mathscr{H}}-t_{B}\right), \quad \frac{\partial p}{\partial x}=b_{2}\left(p^{\prime \prime}-p\right) \\
\frac{\partial t_{O}}{\partial z}=c_{2}\left(t_{\mathscr{H}}-t_{O}\right)
\end{array}\right.
$$

Граничные условия: при $x=0 t_{\varkappa}=t_{\varkappa}^{0}, t_{B}=t_{B}^{0}$, $p=p_{0}$; при $z=0 t_{O}=t_{O}^{0}$. Коэффициенты $a_{1}, b_{1}, c_{1}, a_{2}$, $b_{2}, c_{2}$ определяются соотношениями:

$$
\begin{aligned}
& a_{1}=\frac{\alpha}{c_{\varkappa} g_{\varkappa}}, \quad b_{1}=\frac{r_{D} \beta_{p}}{c_{\varkappa} g_{\varkappa}}, \quad c_{1}=\frac{k}{c_{\varkappa} g_{\varkappa}}, \\
& a_{2}=\frac{\alpha}{c_{2} g_{B}}, \quad b_{2}=1,61 \frac{p_{5} \beta_{p}}{g_{B}}, \quad c_{2}=\frac{k}{c_{2} g_{O}} .
\end{aligned}
$$

Рассматривается линейная теория испарительных охладителей, когда коэффициенты $a_{l}, b_{1}, c_{l}$, $a_{2}, b_{2}, c_{2}$ являются постоянными величинами, а для парциального давление насыщенного пара $p$ " предполагается нелинейная зависимость:

$$
p^{\prime \prime}(t)=690,5 \exp (0,0608 t) .
$$

Представим уравнения ( 6 ) в виде:

$$
\left\{\begin{array}{l}
\frac{\partial t_{\mathscr{x}}}{\partial x}+c_{0} t_{\mathscr{K}}=a_{1} \theta_{B}+b_{1}\left(p-p^{\prime \prime}\right)+c_{1} t_{O}, \quad c_{0}=a_{1}+c_{1} \\
\frac{\partial t_{B}}{\partial x}+a_{2} t_{B}=a_{2} t_{\mathscr{K}}, \quad \frac{\partial p}{\partial x}+b_{2} p=b_{2} p^{\prime \prime} \\
\frac{\partial t_{O}}{\partial z}+c_{2} t_{O}=c_{2} t_{\mathscr{K}}
\end{array}\right.
$$

Рассмотрим численное решение задачи и в качестве алгоритма применим явную разностную схему (метод Эйлера):

$$
\begin{aligned}
& \mathrm{t}_{\% \mathrm{j}}^{\mathrm{i}+1}=\left(1-c_{0} \Delta x\right) t_{ж j}^{i}+\left\lfloor a_{1} t_{B j}^{i}+b_{1}\left(p_{j}^{i}-p_{j}^{\prime \prime}\right)+c_{1} t_{O j}^{i}\right\rfloor \Delta x \\
& t_{B j}^{i+1}=\left(1-a_{2} \Delta x\right) t_{B j}^{i}+a_{2} t_{\text {ж } j}^{i} \Delta x, \\
& p_{j}^{i+1}=\left(1-b_{2} \Delta x\right) p_{j}^{i}+b_{2} \Delta x p_{j}^{\prime \prime} \\
& t_{O{ }_{j+1}}^{i}=\left(1-c_{2} \Delta z\right) t_{O j}{ }_{j}^{i}+c_{2} \Delta z, t_{\dddot{ }}{ }^{i}
\end{aligned}
$$

где $i, j$ определяют соответствующие узловые точки по $x$ и по $z$, а $\Delta x$ и $\Delta z$ - это шаги разностной сетки. Для граничных узловых точек, в соответствии с граничными условиями, получим:

$$
\begin{gathered}
t_{\varkappa j}^{0}=t_{\varkappa}^{0}, t_{B j}^{0}=t_{B}^{0}, p_{j}^{0}=p_{0}, j=1,2, \ldots, n, \\
t_{O 0}^{i}=t_{O}^{0}, i=1,2, \ldots, m
\end{gathered}
$$


Для получения численного решения задачи применена явная разностная схема (метод Эйлера). На рисунках 1В и 1Г представлены характерные профили изменения основных параметров основного «О» (температура охлаждаемого при неизменном влагосодержании потока) и вспомогательного «В» (температура и влагосодержание) воздушных потоков в НИОг (А и Б, соответственно) по длине и высоте расчетного модуля (результаты приведены для начальных параметров воздуха, поступающего в модуль НИОг: П (НВ): $t_{\Gamma}{ }^{1} / t_{\mathrm{M}}{ }^{1} / t_{\mathrm{p}}{ }^{1}=35 / 21 / 14^{0} \mathrm{C} ; x_{\Gamma}{ }^{1}=11$ г/кг и соотношения контактирующих воздушных потоков $l=\mathrm{G}_{\mathrm{o}} / \mathrm{G}_{\mathrm{B}}=0,5$; $1,0 ; 1,5)$

\section{III. ЭКСПЕРИМЕНТАЛЬНЫЙ АНАЛИЗ ВОЗ МОЖНОСТЕЙ ИСПАРИТЕЛЬНЫХ ОХЛАДИ- ТЕЛЕЙ ПРЯМОГО (ГРД) И НЕПРЯМОГО ТИПА НИОГ. ЭКСПЕРИМЕНТАЛЬНОЕ ОБОРУДОВА- НИЕ.}

Принципиальная схема и фото стенда приведены на рисунках 2 и 3. (Обозначения к рисункам: 1А электронагреватель; 1Б - паровой увлажнитель воздуха; 2 - вентилятор; 3 - рабочая камера; 4 распределитель жидкости; 5 - каплеуловитель; 6 расходомер; 7 - рециркуляционная линия; 8, 9 регуляторы расхода воздушного потока; 10 - водяные ротаметры; 11 - секционный измеритель расхода жидкости; 12 - водяной бак; 13 - насос; 14 - фильтр; 15 - водонагреватель; 16 - регулятор температуры жидкости; 17, 18 - ртутный термометр и термометр сопротивления (пары датчиков «сухой-мокрый»); 19 отбор давления; 20 - дополнительная емкость для измерения задержки жидкости; 21 - измерительная линейка; 22 - измерительный комплекс). Стенд обеспечивает возможность изучения рабочих процессов: в испарительном охладителе воды (градирня, ГРД) и охладителе воздуха непрямого типа (НИОг). Воздух забирается из атмосферы вентилятором (2), проходит термовлажностную обработку (подогрев в калорифере 1 и доувлажнение через байпасную линию 8 от воздушного потока, покидающего ИО и (либо) с помощью парового увлажнителя воздуха 1Б) и подается в рабочую камеру 3 , где установлен модуль ИО. Наличие электродвигателя с изменяемым числом оборотов позволяет регулировать расход воздуха. Температура воздуха регулируется с помощью канального электрокалорифера (1) и может составлять до $70^{\circ} \mathrm{C}$. Головная часть стенда, в которой расположен модуль ИО, выполнена со смотровым окном (съемной крышкой) из толстостенного прозрачного плексигласа. Габариты камеры: $460 \times 400 \times 180$ мм (ширина), пропускная способность по полному воздушному потоку до $3500 \mathrm{~m}^{3} /$ ч по газу. На воздушной линии установлен расходомер (6) и регуляторы расхода $(8,9)$. Циркуляцию воды через модуль ИО обеспечивает насос (14) с регулируемой производительностью. Расход воды определяется при помощи блока ротаметров типа РС (10). Вода по напорному трубопроводу поступает в распределительную камеру (4), откуда поступает на орошение насадки. Конструктивное оформление всех
TМА унифицировано. Они решены в виде поперечноточных аппаратов (рисунки ЗБ и В), в которых, в качестве основных элемента насадки используется полимерные многоканальные композиции (ПМ). Водосборник (11) состоит из 5-ти карманов. Это обеспечивает дифференцированный замер расхода жидкости и фиксацию ее продольного сноса воздушным потоком. Расход воздуха измеряется трубкой Пито (19) и микроманометром. Все коммуникации и аппараты теплоизолированы. В схеме предусмотрены измерения температуры и относительной влажности воздушных потоков перед и после рабочей камеры (пары ртутных термометров и термометров сопротивления 17-18), а также температуры циркулирующей воды. Для измерения параметров воздуха используются термопары с многоканальным измерительным преобразователем, (22). Дополнительно осуществлялся замер температур при помощи лабораторных термометров ТЛ-4 с ценой деления $0,1^{\circ} \mathrm{C}$.

Экспериментальный стенд обеспечивает возможность исследования разработанных ИО с насадкой, образованной эквидистантно расположенными многоканальными элементами из ПМ, образующими многоканальную регулярную структуру. Ранее, в ОГАХ, в ходе исследований ИО с насадкой из продольногофрированных элементов из алюминиевой фольги [1-2] варьировали в широких диапазоне значения геометрических параметров: величина эквивалентного диаметра каналов варьировалась в диапазоне 15-20 мм; при этом конструктивная поверхность насадки в единице объема слоя варьировалась в диапазоне $170-200 \mathrm{~m}^{2} / \mathrm{M}^{3}$. Это позволило использовать полученные рекомендации, а также результаты работ $[13,14]$, по указанным параметрам, при создании модулей ИО с новыми типами насадок ПМ. Предварительные расчеты показали возможность использования полимерных материалов в конструкции НИОг, без существенного снижения эффективности процесса, поскольку термическое сопротивление стенок каналов сопоставимо с термическим сопротивлением жидкостной пленки на его поверхностях. Это подтверждается и данными исследования [4]. Однако это требует экспериментальной проверки, также, как и ранее выработанные рекомендации относительно плотности слоя (величин эквивалентных диаметров каналов в «сухой» и «мокрой» частях НИО), соотношения поверхностей тепломассообмена и соотношения воздушных потоков $l=G_{\mathrm{o}} / G_{\mathrm{B}}$. В программе исследований было принято: в качестве базового элемента в модулях ИО использована многоканальные плиты из ПМ; модуль насадки представлял набор эквидистантно расположенных вертикальных элементов с разомкнутыми каналами (рисунок 3), по внутренней поверхности которых подается жидкость, стекающая по наружным поверхностям плит; величина эквивалентного диаметра рабочих каналов составляла в опытах 20 мм; изучали процессы испарительного охлаждения воздуха в НИО, а также процесс в градирне ГРД; рабочий диапазон скоростей движения воздуха в каналах насадки изменялся в диапазоне $w_{\Gamma}=1,0-7,0$ м/с; плотность орошения варьировали в 


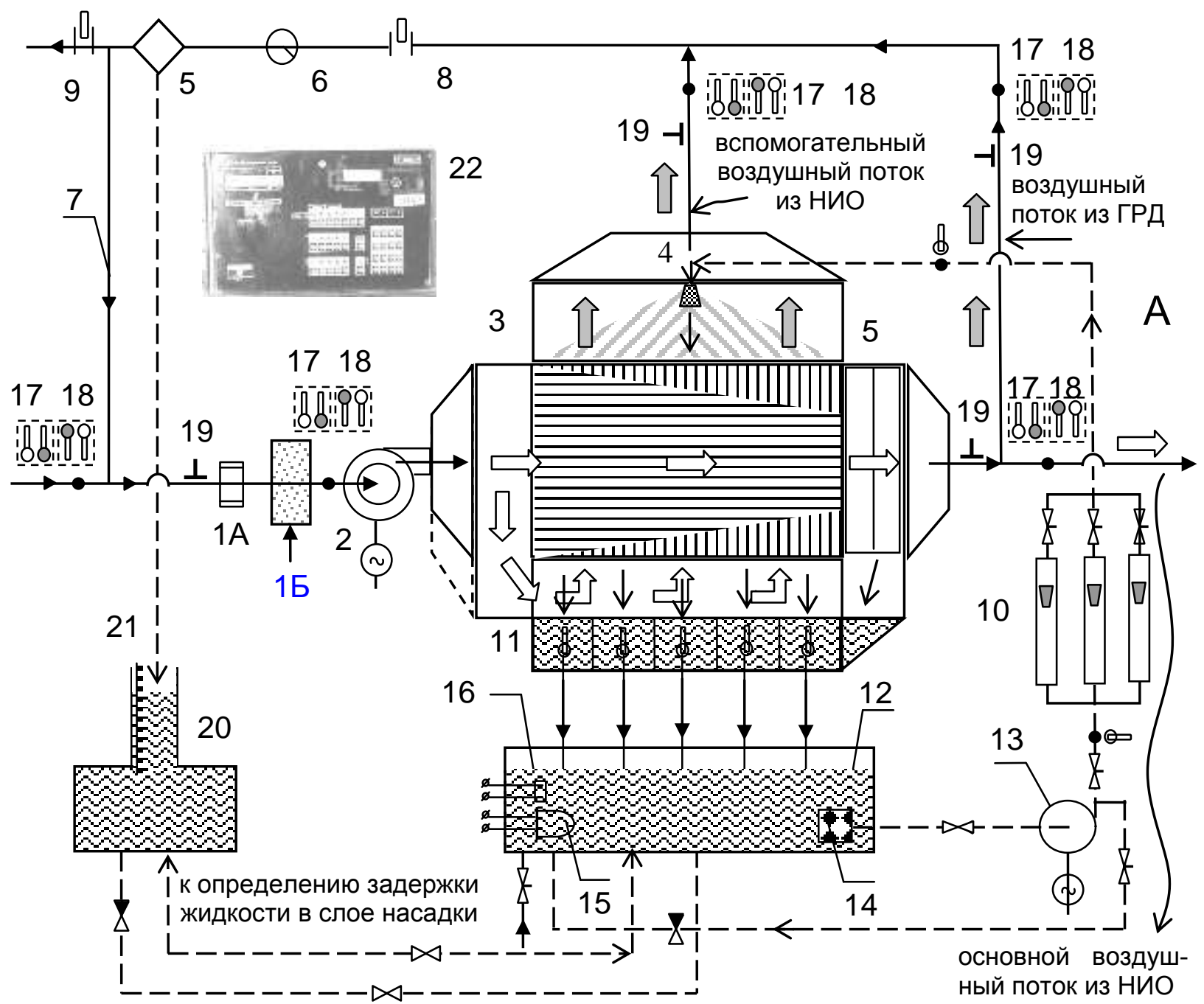

Б
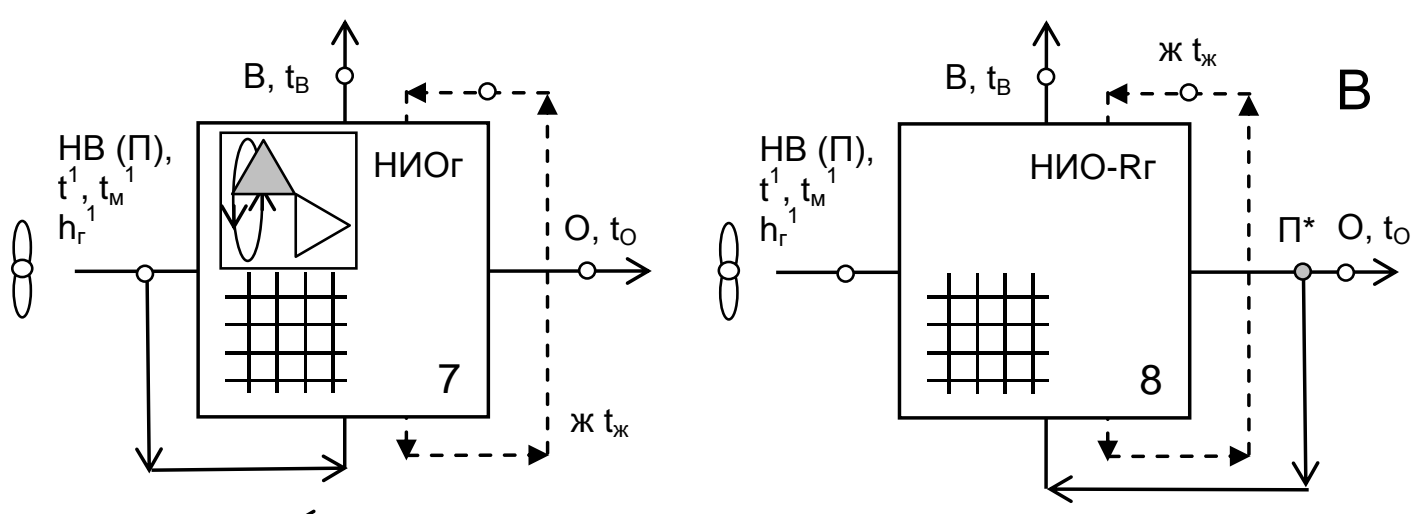

$\Gamma$

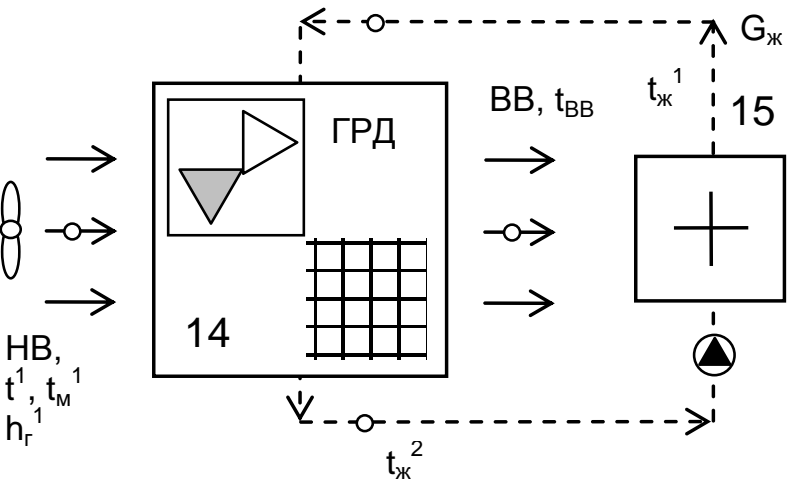

Рисунок 2 - Принципиальная схема экспериментального стенда для исследования поперечноточных тепломассообменных аппаратов при испарительном охлаждении воды (ГРД) и воздуха (НИОг).

Обозначения в тексте 


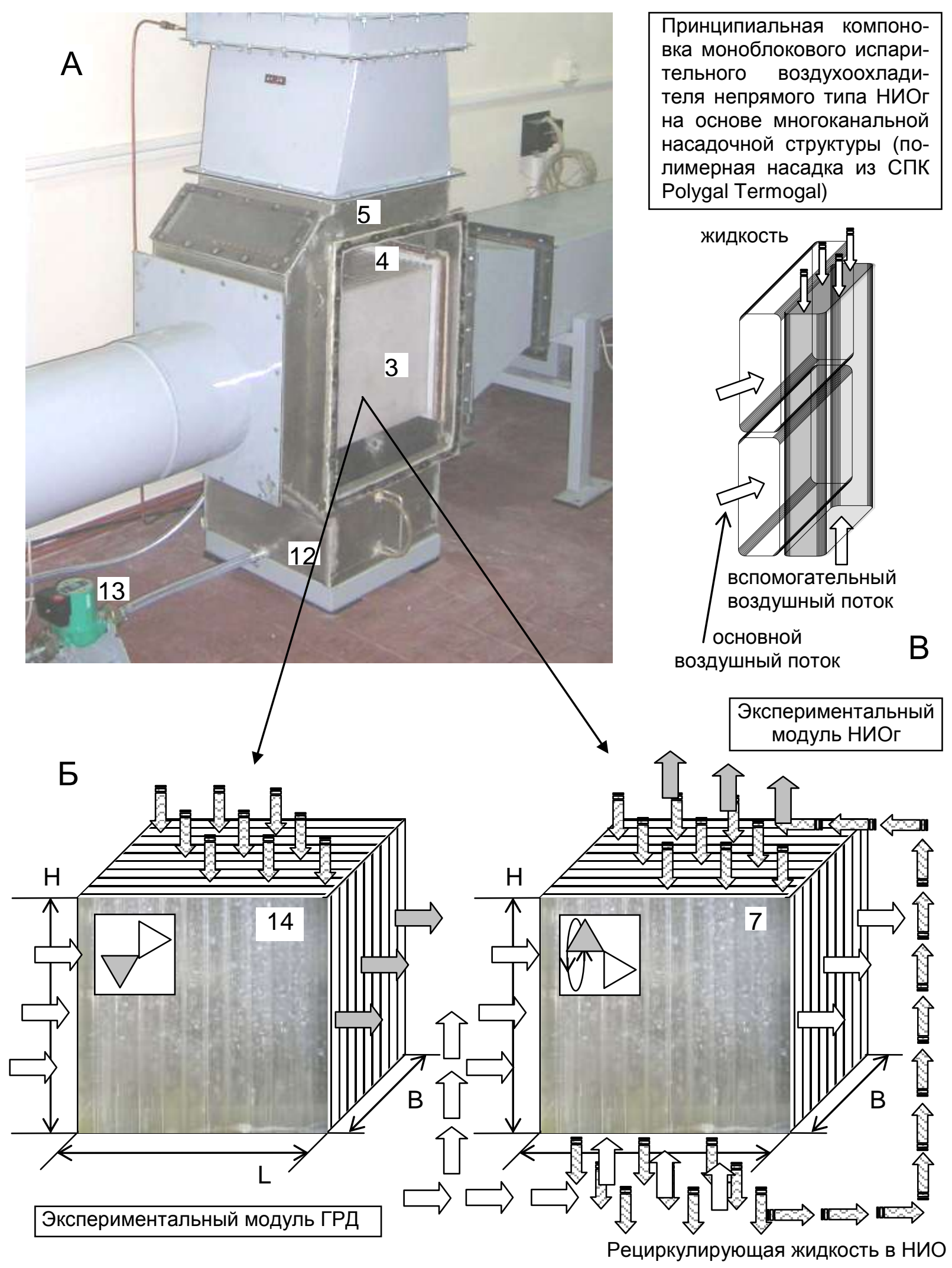

Рисунок 3 - Экспериментальный стенд (головная часть ) для исследования поперечноточных тепломассообменных аппаратов при прямом (Б, ГРД) и непрямом (В, НИО) испарительном охлаждении воды и воздуха, соответственно. А - головная часть стенда; Б и В - экспериментальные модули ГРД и НИО, соответственно. 
диапазоне $q_{ж}=2-18 \mathrm{~m}^{3} / \mathrm{M}^{2} ч$, причем рабочее значение этой величины для воздухоохладителей НИОг не превышало $8 \mathrm{~m}^{3} / \mathrm{M}^{2} ч$, что было обусловлено достаточным развитием величины смоченной поверхности аппарата; в опытах с испарительными водоохладителями величина соотношения расходов газа и жидкости $l=$ $G_{\Gamma} / G_{ж} \approx 1,0$, при этом плотность орошения составляла $q_{\text {ж }}=5-18 \mathrm{~m}^{3} / \mathrm{M}^{2}$. Погрешность измерения основных величин, обусловленная точностью измерений, вычислялась при обработке данных для каждого опыта и составляет: точность сведения теплового баланса - до $12 \%$; экспериментальный материал характеризуется надежной воспроизводимостью.

\section{Экспериментальные результаты. Испарительные водоохладители прямого типа ГРД.}

Устойчивость и предельные нагрузки. На рисунке 4А приведены характерные данные, полученные в ходе аэродинамических испытаний на модулях НИО и ГРД. Из полученных графиков видно: для НИО в пределах эксперимента соотношение расходов основного и вспомогательного воздушных потоков составляло $l$ $\approx G_{\mathrm{O}} / G_{\mathrm{B}}=1,0$; увеличение расхода жидкости в диапазоне значений Gж от «сухого» режима (линия 1) до значения плотности орошения $q_{\text {ж }}=8-12 \mathrm{~m}^{3} / \mathrm{m}^{2} ч$ (линии 2 и 3) не приводит к ощутимому росту потери давления при прохождении воздушного потока через «мокрую» часть насадки НИО (либо насадку ГРД); для противоточной схемы контакта газа и жидкости в каналах ГРД и в «мокрых» каналах НИО (взаимодействие вспомогательного воздушного потока и рециркулирующей водяной пленки, стекающей по стенкам канала) существует критическое значение скорости воздушного потока, $w_{\Gamma}{ }^{*}$, когда развивается явление захлебывания насадки аппарата, характеризующееся обращением противоточной схемы контакта в обращенный прямоток и вынос воздушным потоком жидкости из насадочного слоя (рис. 4А, линия 4); в нашем случае величина $w_{\Gamma}{ }^{*}$ составляет значения $w_{\Gamma}^{*} \approx 6 \mathrm{M} / \mathrm{c}$; явление продольного сноса жидкости в насадке ГРД, при поперечноточной схеме контактирования газа и жидкости, приводящего к неблагоприятному ее перераспределению в объеме насадки и выносу из слоя, также практически отсутствует; установлено, что традиционное явление «захлебывания» (вынос жидкости из насадки аппарата газовым потоком и снижение до нуля пропускной способности аппарата) для принятой нами поперечноточной схемы контактирования потоков газа и жидкости (ГРД) отсутствует полностью, вплоть до значений $w_{2}>8-10$ м/с; переход к поперечноточной схеме обеспечивает снижение уровня $\Delta p$, а следовательно, и снижение удельных энергозатрат по сравнению с противотоком, и возможность значительного повышения нагрузок.

Важнейшей характеристикой аппаратов пленочного типа является количество удерживаемой жидко-

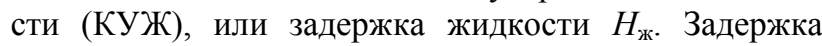
жидкости в слое насадки реально обеспечивает высокое значение поверхности тепломасообмена, и, тем самым, достаточно высокую эффективность процесса испарительного охлаждения. Эта величина определя- ет реальную поверхность переноса в слое насадки и особенно важная для насадок РН выполненных на основе многоканальных полимерных структур ПМ. В работе, как и в более раннем исследовании [2], был использован циркуляционный метод, основанный на принципе сохранения количества жидкости при работе по замкнутому контуру. Жидкость подается в аппарат из калиброванной емкости (12) и в нее же сливается. Разница между уровнями жидкости до включения аппарата и во время его работы пропорциональна удерживающей способности слоя насадки. Во время работы уровень в емкости меняется также из-за уноса жидкости и ее испарения. Разработанная методика позволяет учесть эти составляющие и определить реальную задержку жидкости. На противоточной системе вода-воздух предварительно было показано, что зависимость падения уровня жидкости в сливном баке (калиброванной емкости 20 - дополнительная емкость для измерения задержки жидкости; 21 измерительная линейка) после включения аппарата, обусловленного уносом и испарением, можно экстраполировать прямой линией при стационарном режиме работы и определить задержку по падению уровня в начальный момент времени. Жидкость, удержанную в сепарационной зоне, определяли методом отсечки:

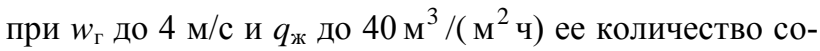
ставляет менее $25 \%$ от всей жидкости, удерживаемой в аппарате. Точность эксперимента, определяемая по максимальной погрешности средств измерения, колебалась от $\pm 30 \%$ при малых значениях удерживающей способности $\left(H_{\text {ж }} \sim 0,510^{-2} \mathrm{м}\right)$ до \pm 3 при больших $\left(H_{ж} \sim\right.$ $\left.710^{-2} \mathrm{M}\right)$. Для малых значений задержки жидкости была проведена статистическая оценка точности по большому числу экспериментальных точек: границы погрешности результатов измерений находятся в пределах $\pm 8-12 \%$, с доверительной вероятностью 0,95 . Накопление жидкости в объеме насадки происходит практически мгновенно и так формируется общая поверхность тепломасообмена. На рисунках 4Б и В приведены зависимости задержки жидкости в слое насадки, в зависимости от расходов воды и воздуха.

В качестве естественного предела охлаждения воды в градирне принято рассматривать температуру воздуха по мокрому термометру на входе в аппарат $t_{\mu}^{1}$. На выходе из аппарата, в качестве предельного рассматривают состояние насыщенного воздуха, имеющего температуру поступающей на охлаждение воды $t_{\text {ж }}^{1}$ (воздух с энтальпией $h_{\Gamma}^{2^{* *}}$ ). Эффективность

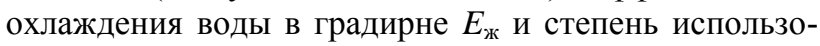
вания воздуха в аппарате $\mathrm{E}_{\text {г }}$ (равная отношению тепла, вынесенного из аппарата потоком воздуха, к предельному его количеству, определяемому равенством $h_{\Gamma}^{2}=h_{\Gamma}^{{ }^{2 *}}$.) характеризуются:

$$
E_{ж}=\frac{\left(t_{\varkappa}^{1}-t_{\dddot{ }}^{2}\right)}{\left(t_{\varkappa}^{1}-t_{M}^{1}\right)} ; \quad E_{\Gamma}=\frac{\left(h_{2}^{2}-h_{2}^{1}\right)}{\left(h_{2}^{2 *}-h_{2}^{1}\right)}
$$

Очевидно, чем выше при данном $E_{\text {ж }}$ степень использования воздуха, тем ниже расход энергии на привод вентилятора водоохладителя и ниже удельные 


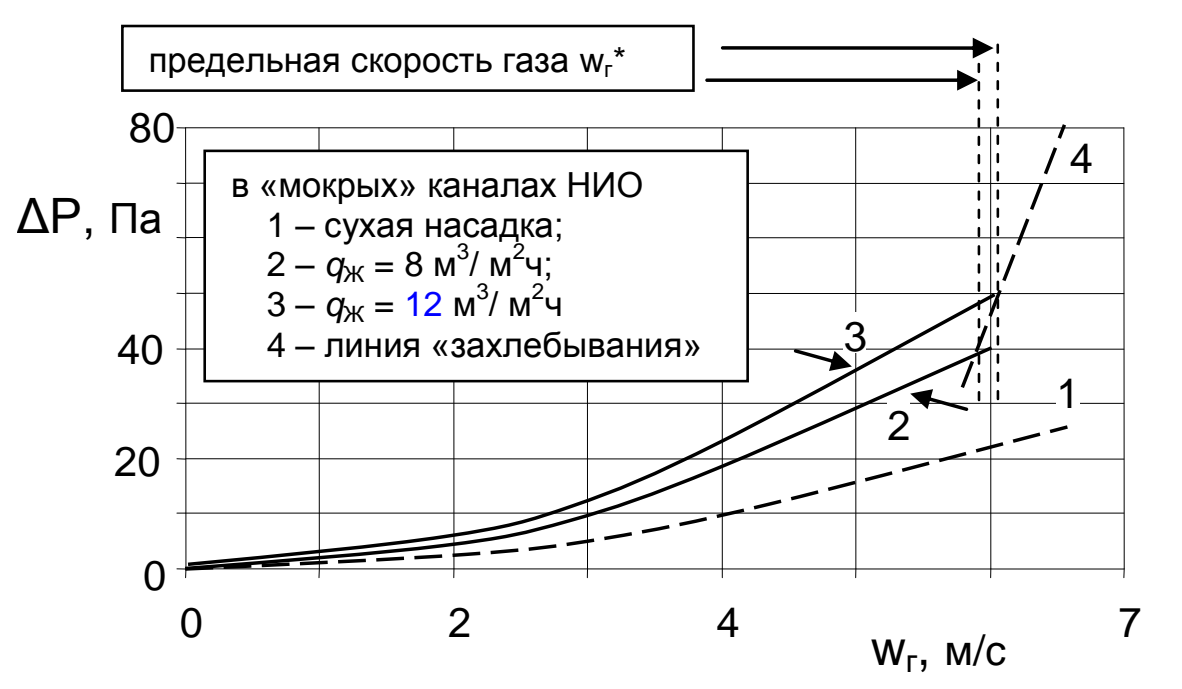

A

HИOr

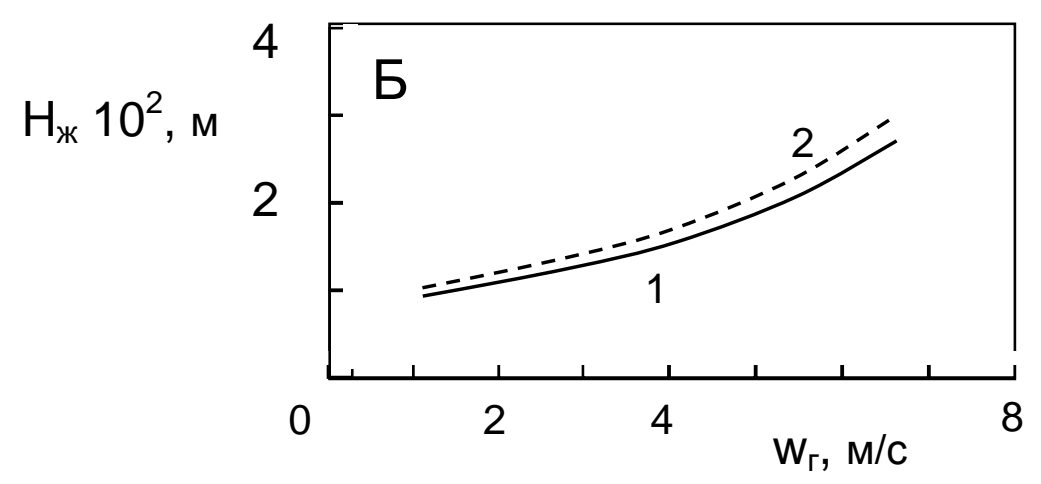

ГРД

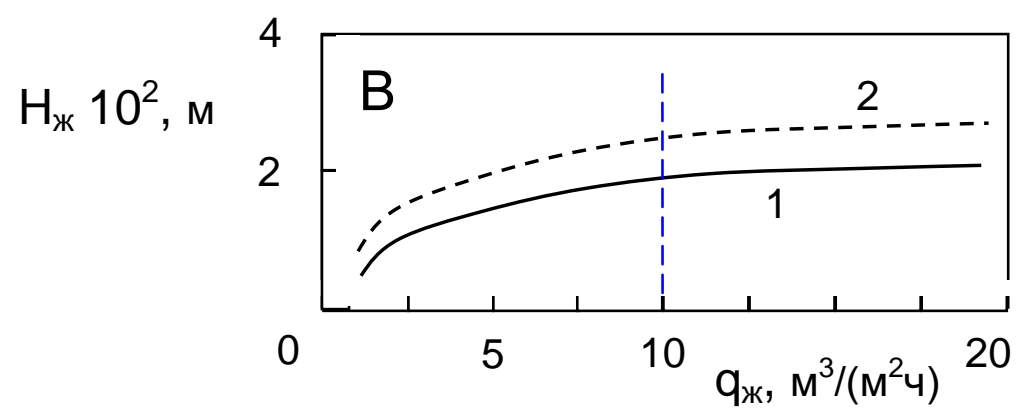

Рисунок 4 - Гидроаэродинамические характеристики насадки испарительных охладителей газа и жидкости.

А - потеря давления в мокрых каналах апарата НИО (вспомогательный воздушный поток и рециркулирующая вода), в зависимости от расходов газа и жидкости;

Б и В - влияние расходов газа [при $q_{\text {ж}}=8 \mathrm{M}^{3} /\left(\mathrm{M}^{2} ч\right)$ (1) и $12 \mathrm{M}^{3} /\left(\mathrm{M}^{2} ч\right)$ (2)] и плотности орошения жидкостью [при $w_{\mathrm{r}}=2,5 \mathrm{~m} / \mathrm{c}(1)$ и $\left.4,0 \mathrm{~m} / \mathrm{c}(2)\right]$ на величину задержки жидкости в слое полимерной насадки (CПК Polygal Termogal). 
энергозатраты. Для зависимости $E=f(\Lambda)$ можно получить эмпирические выражения для расчета всех основных величин:

$$
\begin{gathered}
\mathrm{E}_{\text {ж }}=\mathrm{f}\left(1=\mathrm{G}_{\mathrm{\Gamma}} / \mathrm{G}_{\text {ж}}, t_{\text {ж }}^{1}, t_{\mu}^{1}\right) \text { и } \\
\mathrm{E}_{\text {Г }}=\mathrm{f}\left(\mathrm{l}=\mathrm{G}_{\Gamma} / \mathrm{G}_{\text {}}, t_{\text {ж }}^{1}, t_{\mu}^{1}\right) \\
\mathrm{E}_{\text {ж}}=\mathrm{c}\left(1-\mathrm{e}^{-1.1 \Lambda}\right), \\
\mathrm{E}_{\text {Г }}=\mathrm{c}\left(1-\mathrm{e}^{-1.1 \Lambda}\right) \Lambda^{-1}
\end{gathered}
$$

На рисунках 5 и 6 приведены полученные экспериментальные результаты по эффективности процессов в испарительных водоохладителях прямого типа ГРД. На рисунке 5А приведены данные, полученные авторами на насадке из полимерных материалов со сложнопрофилированным каналом сплошная линия с экспериментальными точками), наряду с ранее полученными в ОГАХ результатами на насадках пленочного типа из различных материалов $[13,14]$. Оптимальное значение соотношения потоков газа и жидкости составляет $l=G_{\Gamma} / G_{Ж} \approx 1,0$, при этом эффектив-

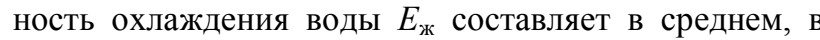
зависимости от величины $\Lambda$, диапазон значений 0,5-0,88. Отметим, что ранее, в опытах с ГРД с насадкой из теплопроводного материала - алюминиевой фольги (кривая $1,[2])$ величина $\Lambda$ составляла в среднем 0,8-0.9, при несколько более высоком значении эффективности процесса. В выражениях для величины $E_{\text {ж }}(17)$ величина $c$ для исследованных типов насадок составляет с $\approx 0,88-0,9$. Ранее было получено:

- в работе [2] для насадки из алюминиевой гофрированной фольги $\left(d_{\ni}=12 \mathrm{Mм} ; \mathrm{H}_{\mathrm{PH}}=400\right.$ мм.; величина $c \approx 0,82-0,84$;

- в работе [1] для насадки из полимерного материала мипласта (капиллярно-пористой структуры) получено $c \approx 0,83$;

- в работе [13] для насадки из многоканальных поликарбонатных плит (поперечный ток; каналы с регулярной шероховатостью поверхности; $d_{\ni}=15$ мм, $H_{\mathrm{PH}}=500$ мм.); величина $c \approx 0,85$;

- в работе [14] для насадки из многоканальных многослойных поликарбонатных плит (противоток; $d_{\ni}=15 \mathrm{Mм}, H_{\mathrm{PH}}=400$ мм.); величина $c \approx 0,86-0,87$.

Величина показателя в уравнениях определяется конструкцией насадки аппарата, обеспечившей реальный рост поверхности переноса в единице объема слоя насадки, за счет реальной задержки жидкости. Этим объясняется некоторый рост эффективности при переходе на полимерные материалы ПМ, сравнительно с насадкой из алюминиевой фольги [2], в работах Франко [13], Хассана [14] и по нашим данным. Рост величины задержки жидкости в насадочном слое здесь обусловлен сложной конструкцией профиля каналов. На рисунке 6 приведены экспериментальные данные по эффективности процесса охлаждения воды в градирне, как функции начального влагосодержания (А) и температуры наружного воздуха (Б)

\section{Испарительные воздухоохладители непрямого ти- па НИОг}

Был проведен анализ работы испарительного воздухоохладителя НИОг (IECg) для различных соотношений основного и вспомогательного воздушных потоков $l=G_{\mathrm{o}} / G_{\mathrm{B}}: 1-1,5 ; 2-1,0 ; 3-0,5$ (рисунок 7Б), температур (7В) и влагосодержаний (7А) на входе в НИОг. Анализ выполнен как на основе разработанной математической модели процессов в НИОг, так и на основании полученных авторами экспериментальных результатов. Полученные теоретические и экспериментальные результаты находятся в хорошем соответствии, несколько расходясь с ростом расхода вспомогательного воздушного потока. Применительно к процессу в НИОг в качестве естественного предела охлаждения основного и вспомогательного воздушных потоков можно рассматривать температуру полного воздушного потока по мокрому термометру $t_{\mathrm{m}}{ }^{1}$, увеличенную на некоторую величину, в зависимости от соотношения расходов воздушных потоков в аппарате $l=G_{\mathrm{O}} / G_{\mathrm{B}}: t^{0}=t_{\mathrm{M}}{ }^{1}+\Delta t^{*}$, что связано с процессом переноса тепла в «явном» виде от основного к вспомогательному потоку через разделительную стенку и стекающую по поверхности «мокрого» канала жидкостную пленку, и соответствующим повышением температуры рециркулирующей через «мокрую»

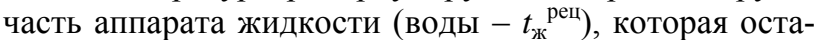
ется в цикле постоянной. Термическая эффективность НИОг по основному и вспомогательному потокам составляет:

$$
\begin{gathered}
E_{\mathrm{O}}=\left(t_{\mathrm{o}}{ }^{1}-t_{\mathrm{o}}{ }^{2}\right) /\left(t_{\mathrm{o}}{ }^{1}-t^{0}\right) ; E_{\mathrm{B}}=\left(t_{\mathrm{B}}{ }^{1}-t_{\mathrm{B}}{ }^{2}\right) /\left(t_{\mathrm{B}}{ }^{1}-t^{0}\right) \\
E_{\mathrm{O}}=f\left(l=G_{\mathrm{O}} / G_{\mathrm{B}}, t_{\Pi}, t^{0}\right) ; E_{\mathrm{B}}=f\left(l=G_{\mathrm{O}} / G_{\mathrm{B}}, t_{\Pi}, t^{0}\right)
\end{gathered}
$$

Получены следующие значения термической эффективности процесса, соответственно реальным значениям предела охлаждения $t^{0}: l=G_{\mathrm{o}} / G_{\mathrm{B}}=1,5$, $E_{\mathrm{O}}=0,45 ; l=G_{\mathrm{o}} / G_{\mathrm{B}}=1,0, E_{\mathrm{O}}=0,65 ; l=G_{\mathrm{o}} / G_{\mathrm{B}}=0,5$, $E_{\mathrm{O}}=0,89$. Увеличение доли вспомогательного потока последовательно повышает глубину охлаждения основного потока, одновременно повышая и удельные энергозатраты на единицу «продукта». Обратим внимание на последовательное приближение состояния вспомогательного воздуха к равновесной кривой $\varphi=100 \%$, что является следствием приближения к естественному пределу охлаждения.

Авторами был приведен сравнительный анализ работы испарительного воздухоохладителя непрямого типа НИО (пунктирные линии) и воздухоохладителя НИО-Rг. Анализ выполнен для условия: $l=G_{\mathrm{o}} / G_{\mathrm{B}}=1,0$ для обоих схем НИО. Достигнуто снижение температуры основного воздушного потока от $t_{\mathrm{o}}=26,5^{\circ} \mathrm{C}$ для НИО $\left(t_{\mathrm{B}}=25,5^{\circ} \mathrm{C} ; \varphi_{\mathrm{B}}=95 \%\right)$ до $\mathrm{t}_{\mathrm{o}}=21,0^{\circ} \mathrm{C}$ для НИО/R (параметры вспомогательного воздушного потока $t_{\mathrm{B}}=27,0^{\circ} \mathrm{C}, \varphi_{\mathrm{B}}=100 \%$ ). Следует обратить особое внимание на выходные параметры вспомогательного воздушного потока, покидающего воздухоохладитель НИО-Rг. 


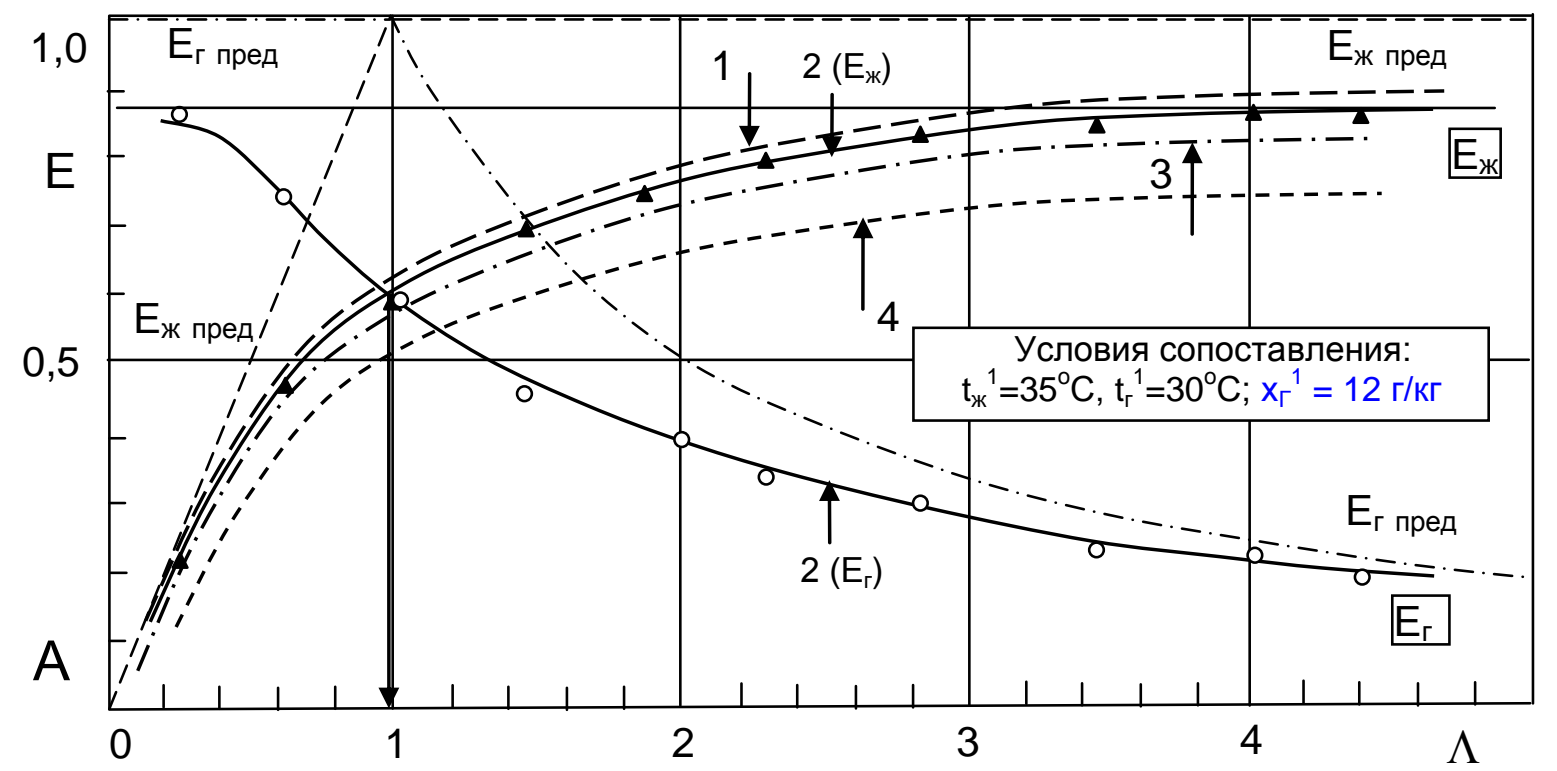

1. Данные работы [АвД дд]: насадка из алюминиевой гофрированной фольги $\left(\mathrm{d}_{\ni}=\right.$ $12 \mathrm{Mm} ; \mathrm{H}_{\mathrm{PH}}=400 \mathrm{~mm}$.).

2. Данные автора: насадка из многоканальных многослойных поликарбонатных плит (поперечный ток; $\mathrm{d}_{\ni}=15 \mathrm{Mm}, \mathrm{H}_{\mathrm{PH}}=500 \mathrm{Mм}$.); сплошная линия с экспериментальными точками;

3. Данные работы РН из ПМ [х-н]: насадка из многоканальных многослойных поликарбонатных плит (противоток; $\mathrm{d}_{\ni}=15 \mathrm{Mm}, \mathrm{H}_{\mathrm{PH}}=400 \mathrm{Mм}$. );

4. Данные работы РН из ПМ [франко]: насадка из многоканальных поликарбонатных плит (поперечный ток; каналы с регулярной шероховатостью поверхности; $d_{\ni}=$ $15 \mathrm{Mm}, \mathrm{H}_{\mathrm{PH}}=500 \mathrm{Mm}$.)

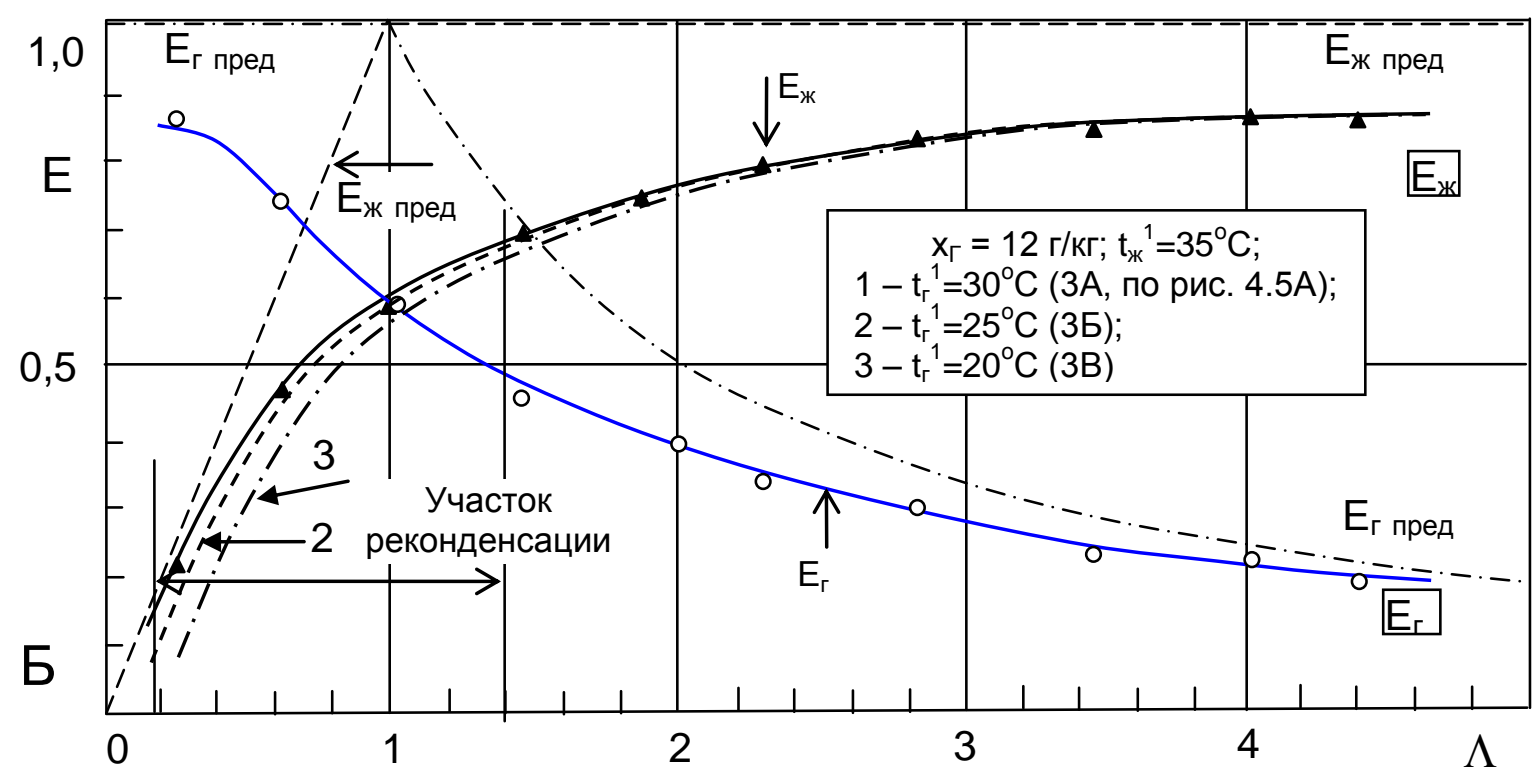

Рисунок 5 - Эффективность процесса охлаждения воды и использования воздушного потока в градирне как функции характеристического числа $\Lambda$ (А). Экспериментальные данные автора (сплошная линия) получены на поперечноточной насадке из многоканальных многослойных поликарбонатных плит с параметрами слоя: $d_{\ni}=15 \mathrm{MM}, H_{\mathrm{PH}}=400 \mathrm{Mм}$.

Б - Влияние реконденсации на эффективность процесса испарительного охлаждения: влияние соотношения потоков и начальной температуры 


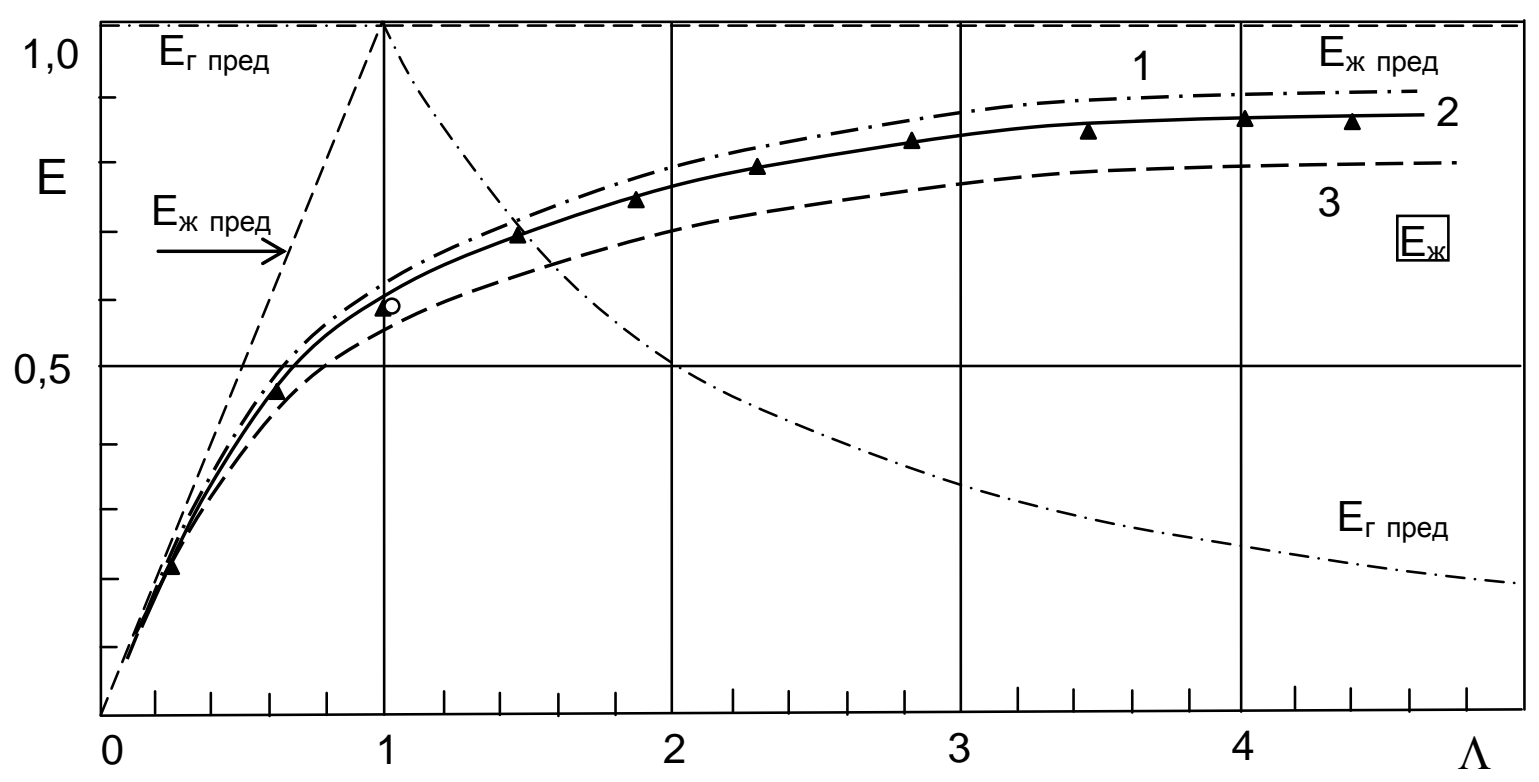

Влияние влагосодержания воздуха на входе в градирню. Условия проведения эксперимента: $t_{\text {ж }}{ }^{1}=35^{\circ} \mathrm{C}, t_{\Gamma}{ }^{1}=30^{\circ} \mathrm{C}$, при: $1-x_{\Gamma}=9 г / \kappa г, 2-x_{\Gamma}=12$ г/кг, $3-x_{\Gamma}=16 г / \kappa г$

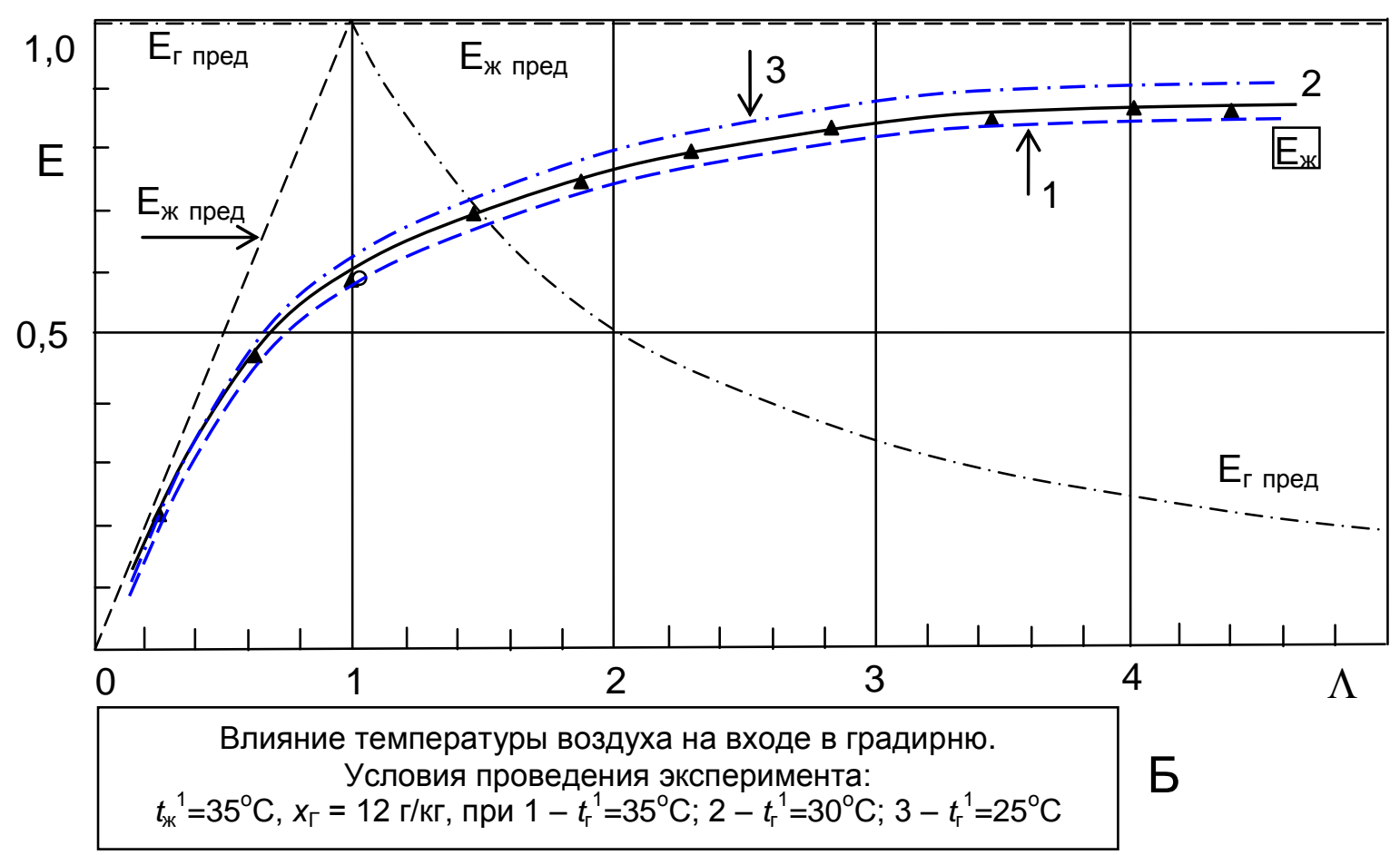

Рисунок 6 - Эффективность процесса охлаждения воды в градирне, как функции характеристического числа $\Lambda$. Экспериментальные данные.

А - Влияние начального влагосодержания наружного воздуха.

Б - Влияние температуры наружного воздуха. 



Рисунок 7 - Экспериментальные результаты, полученные для испарительного воздухоохладителя НИО (IEC) при различных: А и В - влагосодержаниях и температурах наружного воздуха; Б - соотношениях основного и вспомогательного воздушных потоков $l=G_{\mathrm{o}} / G_{\mathrm{B}}: 1-0,5 ; 2-1,0 ; 3-1,5$. 
Практически, в отличие от процессов в НИОг, изменение состояния вспомогательного воздушного потока в НИО-Rг протекает вдоль линии $\varphi_{\mathrm{B}}=100 \%$, что может приводить к реконденсации и снижению эффективности охлаждения. Это обстоятельство, крайне важное для развития техники испарительного охлаждения, практически не учитывается в публикациях последних лет [7-9], что может приводить к искажениям полученных результатов. Влияние на характер протекания процесса в НИО-Rг может оказы-

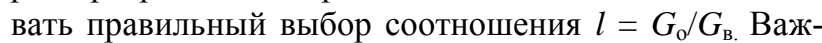
ную роль при этом имеет и соотношение вспомогательного воздушного потока и потока рециркулирующей воды.

\section{ВЫВОДЫ}

1. Сравнительно с прямым испарительным охлаждением воздуха, охлаждение воздушного потока в охладителе непрямого типа НИОг обеспечивает возможность «сухого» охлаждения воздуха, без его увлажнения, что открывает пути к построению СКВ на основе «основного» воздушного потока и перспективы построения комбинированных схемных решений, где в первой ступени охлаждения используется воздухоохладитель НИО, обеспечивающий снижение предела охлаждения в последующих степенях охлаждения (например, градирня ГРД);

2. Авторами предложена математическая модель процессов совместного теполомасообмена в НИОг, позволяющая учесть опасность реконденсации во вспомогательном воздушном потоке, что принципиально важно при переходе к испарительному охладителю воздуха или воды HИO-Rг;

3. Переход на схемное решение испарительного воздухоохладителя НИО-Rг обеспечивает, сравнительно с традиционным оформлением воздухоохладителя непрямого типа, существенное снижение температуры воздушного потока, но требует рассмотрения опасности возникновения «реконденсации» во вспомогательном воздушном потоке, непосредственно контактирующем с рециркулирующей через «мокрую» часть аппарата воды; решение проблемы реконденсации в испарительных воздухоохладителях НИОг и НИО-Rг определяется правильным выбором соотношения контактирующих потоков $l=G_{0} / G_{\text {в }}$ для испа-

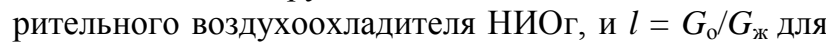
испарительного водоохладителя НИОж.

\section{ЛИТЕРАТУРА}

1. Альтернативная энергетика. Солнечные системы тепло-хладоснабжения: монография / А. В. Дорошенко, М. А. Глауберман. - Одесса: ОНУ, 2012. $446 \mathrm{c.}$

2. Дорошенко А. Компактная тепломассообменная аппаратура для холодильной техники (теория, расчет, инженерная практика). Докторская диссертация,
Одесский институт низкотемпературной техники и энергетики. Одесса.- 1992. - т. 1. - 350 с., т. 2. - 260 с. 3. Лойцянский Л. Г. Механика жидкости и газа. М.: «Наука». - 1973. - 848 с.

4. John L., McNab, Paul McGregor, 2003, Dual Indirect Cycle Air-Conditioner Uses Heat Concentrated Dessicant and Energy Recovery in a polymer Plate Heat Exchanger. $21^{\mathrm{h}}$ International Congress of Refrigeration IIR/IIF, Washington, D.C, ICR0646.

5. Guangming Chen, Alexander Doroshenko, Paul Koltun, Kostyantyn Shestopalov. Comparative field experimental investigations of different flat plate solar collectors, Solar Energy, 115, pp. 577-588, 2015.

6. Guangming Chen, Kostyantyn Shestopalov, Alexander Doroshenko, Paul Koltun. Polymeric materials for solar energy utilization: a comparative experimental study and environmental aspects, Polymer-Plastics Technology and Engineering, 54, pp. 796-805, 2015

7. USA Patent No.: US 6497107 B2. Dec. 24, 2002. Method and Apparatus of Indirect-Evaporative Cooling.

8. Maisotsenko V., Lelland Gillan, M. 2003, The Maisotsenko Cycle for Air Desiccant Cooling. $21^{\mathrm{h}}$ International Congress of Refrigeration IIR/IIF, Washington, D.C.

9. Denis Pandelidis, Sergey Anisimov, William M. Worec. Performance study of the Maisotsenko Cycle heat exchangers in different air-conditioning applications. Intern. Journal of Heat and Mass Transfer 81 (2015) 207221

10. Koltun, P. Life Cycle Assessment of a Conventional and Alternantive Air-Conditioning Systems. P. Koltun, S. Ramakrishnan, A. Doroshenko, M. Kontsov. $21^{\mathrm{h}}$ International Congress of Refrigeration IIR/IIF, Washington, D.C, ICR0140, 2003. P. 45-57.

11. Дорошенко А. В. Солнечные многоступенчатые абсорбционные холодильные системы на основе тепломасообменных аппаратов пленочного типа // А.В. Дорошенко, А.Р. Антонова, К.В. Людницкий/. Холодильная техника и технология. $-2015 .-51(2)-$ С. 25 31

12. Дорошенко А. В., Людницкий К. В. Солнечные холодильные системы на основе абсорбера с внутренним испарительным охлаждением. // Холодильная техника и технология. - 51 (3) - 2015. - С. 42-52.

13. Дорошенко А. В., Франко Ю. А., Слободенюк М. И., Кириллов В. Х. Абсорбционные холодильные системы с солнечными газо-жидкостными коллекторами. Холодильна техніка і технологія. -2008. №.6 (116). - С. 32-36.

14. Хассан Сади Ибрахим. Теплофизические основы многофункциональных солнечных систем. Часть II. / Дорошенко А.В., Джамаль Камаль Хусейн, Хассан Сади Ибрахим, Глауберман М.А. // Физика аэродисперсных систем . - 2011. - № 48. - С. 16-27.

Отримана в редакції 02.06.2016, прийнята до друку 01.07.2016 


\section{A. V. Doroshenko ${ }^{\bowtie}$, V. Kh. Kirillov, A. R. Antonova, K. V. Lyudnitskij, V. V. Melekhin}

Odessa National Academy of Food Technologies, 112 Kanatnaya str., Odessa, 65039, Ukraine

$\triangle$ e-mail: dor_av@i.ua

\section{DIRECT (COOLING TOWER) AND INDIRECT TYPES GASES AND LIQUIDS EVAPORATIVE COOLERS WITH LOWERED COOLING LIMIT}

The fundamental decisions of water and air evaporative coolers of direct and indirect type are developed with the lowered limit of cooling (in relation to the temperature of wet thermometer of entering to the cooler current of air). Heatmass-transfer apparatus of film-type is executed on the basis of multichannel compositions from polymeric materials with the channels of intricate configuration. A mathematical model describing the common heat-mass-transfer processes in the evaporative coolers of indirect type (IECg and IEC-Rg) has been proposed, the comparative analysis of the developed evaporative coolers abilities has been carried out on the basis of the obtained experimental data on heatmass-transfer processes efficiency. The initial parameters (temperature and humidity ratio) of air flow and contacting flows of gas and liquid correlation were varied in the experiment. The special attention has been spared to the features of heat-mass-transfer processes flowing at the low temperature water and air cooling.

Keywords: Direct Evaporative Cooling (Cooling Tower); Indirect Evaporative Cooling; Heat-Mass-Transfer Apparatus; Film-Type Apparatus; Efficiency of Process

\section{REFERENCES}

1.Doroshenko, A. V., Glauberman, M. A. (2012). Alternative energy. Solar heating and cooling systems. Odessa, ONU Publ., 446 p.

2.Doroshenko, A. V. (1992). Kompaktnaia teplomassoobmennaia apparatura dlia kholodilnoi tekhniki (teoriia, raschet, inzhenernaia praktika) [Compact heat and mass transfer equipment for refrigerating technics (theory, computation, engineering practice). Dokt. Diss.] Odessa, T. 1350 p., T. 2.260 p.

3.Loitsianskii, L. G. (1973) Mekhanika zhidkosti i gaza. Moskow: Nauka, 848 p.

4.John L., McNab, Paul McGregor (2003). Dual Indirect Cycle Air-Conditioner Uses Heat Concentrated Dessicant and Energy Recovery in a polymer Plate Heat Exchanger. $21^{\text {st }}$ International Congress of Refrigeration IIR/IIF, Washington, D.C., ICR0646.

5.Chen, G., Doroshenko, A., Koltun, P., Shestopalov, K. (2015). Comparative field experimental investigations of different flat plate solar collectors. Solar Energy, 115, 577 588. DOI: http://dx.doi.org/10.1016/j.solener.2015.03.021 6. Guangming Chen, Kostyantyn Shestopalov, Alexander Doroshenko, Paul Koltun (2015). Polymeric materials for solar energy utilization: a comparative experimental study and environmental aspects. Polymer-Plastics Technology and Engineering, 54(8), 796-805 DOI: https://doi.org/10.1080/03602559.2014.974185

7.USA Patent No.: US6497107 B2. Dec. 24, 2002. Method and Apparatus of Indirect-Evaporative Cooling. URL: http://www.google.com/patents/US6497107

8.Maisotsenko, V., Lelland Gillan, M. (2003). The Maisotsenko Cycle for Air Desiccant Cooling. $21^{\text {st }}$ International Congress of Refrigeration IIR/IIF, Washington, D.C.
9.Denis Pandelidis, Sergey Anisimov, William $M$. Worec (2015). Performance study of the Maisotsenko Cycle heat exchangers in different air-conditioning applications. Intern. Journal of Heat and Mass Transfer, 81, 207221, DOI: https://doi.org/10.1016/j.ijheatmasstransfer.2014. 10.033

10. Koltun, P., Ramakrishnan, S., Doroshenko, A., Kontsov, M. (2003). Life Cycle Assessment of a Conventional and Alternantive Air-Conditioning Systems. $21^{\text {st }}$ International Congress of Refrigeration IIR/IIF, Washington, D.C, ICR0140, P. 45-57.

11. Doroshenko, A. V., Antonova, A. R., Lyudnitsky, K. V. (2015). Solar multi-stage absorption refrigeration systems based on film type heat-mass exchange apparatuses. Refrigeration engineering and technology, 51(2), 25-31, (in Russian).

DOI: http://dx.doi.org/10.15673/0453-8307.2/2015.39349

12. Doroshenko, A. V., Lyudnitsky, K. V. (2015) Solar refrigeration systems based on the absorber with internal evaporative cooling. Refrigeration engineering and technology, 51(3), 42-52, (in Russian).

DOI: http://dx.doi.org/10.15673/0453-8307.3/2015.42639

13. Doroshenko, A. V., Franko, Yu. A., Slobodenyuk, M. I., Kirillov, V. Kh. (2008) Absorbing refrigeration systems with gaz-liquid solar collectors. Refrigeration engineering and technology, No.6 (116), 32-36, (in Russian).

14. Doroshenko, A. V., Jamal Kamal Hussein, Hassan Sadi Ibrahim, Glauberman, M. A. (2011). Teplofizicheskie osnovy mnogofunktsionalnykh solnechnykh sistem. Part II. Fizika aerodispersnykh system, No.48, 1627, (in Russian).

Received 02 June 2016 Approved 01 July 2016 Available in Internet 31 August 2016 